\title{
UMA TEORIA DO CONFLITO NÃO MAQUIAVELIANO: $O$ CASO DE JAMES HARRINGTON
}

\author{
Luís Falcão \\ Professor adjunto do Departamento de Ciência Política e do PPGCP da Universidade Federal \\ Fluminense (UFF).Niterói, RJ, Brasil. E-mail: luis.alves.falcao@gmail.com \\ Orcid: 0000-0003-3785-626X \\ http://dx.doi.org/10.1590/0102-143174/111
}

\section{Introdução}

Frequentemente, estudiosos da história do pensamento político buscam agrupar determinados autores ou sistemas teóricos tendo por base uma característica em comum, embora nem sempre com a devida preocupação em se perscrutar as linhas de continuidade e as de ruptura. Maquiavel é, certamente, um dos pensadores consagrados que mais suscitaram esse tipo de abordagem sobre o desenvolvimento de seu pensamento e recepção. Há a política maquiavélica do lugar-comum, isto é, da maldade e da perfídia, da força e da fraude; há o maquiavelismo da realpolitik; há o maquiavelismo da unificação nacional e da Razão de Estado; e há, dentre outros ainda, o Maquiavel republicano. Essa última versão é a que tem produzido mais frutos nas últimas décadas, particularmente, relacionando-o aos termos centrais da tradição atlântica e do republicanismo inglês (Pocock, 2003; Rahe, 2008; Skinner, 1998; Sullivan, 2004).

Essa leitura divide com uma outra, ainda mais recente, a de um Maquiavel mais democrático e popular do que propriamente republicano (McCormick, 2011; Vatter, 2010), a ideia de que o conflito político é capaz de gerar liberdade, 
grandeza e império das leis (Adverse, 2007; Ballestrini, 2010; Bignotto, 1991; Geuna, 1998; Pedullà, 2011). Desse modo, esforços interpretativos têm sido realizados no sentido de classificar as linhas de continuidade do republicanismo maquiaveliano e, pelo menos, desde a fundadora obra de Pocock, elas se estendem pelas guerras civis inglesas no caminho de atravessar o Atlântico.

Um ponto chave nessa linha de continuidade se deve à obra de James Harrington (1611-1677). Essencialmente, ele é considerado pela maioria de seus intérpretes como continuador de temas centrais desse republicanismo florentino, basilarmente, de inspiração maquiaveliana. O império das leis, o governo misto, a liberdade, a cidadania armada e a redução aos princípios seriam, assim, os termos chave da empreitada do maquiavelismo inglês no século XVII. Contudo, quando o tema do conflito é considerado dentro do sistema teórico de Harrington, via de regra, seus estudiosos o negam e o alocam na tradição da harmonia e concórdia de matriz ciceroniana e humanista, oposta a Maquiavel. Nesse cenário, a questão que se impõe, entretanto, é justamente questionar a pertinência de tal interpretação. Primeiramente, não se deve reduzir toda e qualquer forma de conflito político aos termos de Maquiavel, qual sejam, de que há homens que desejam dominar e os que desejam não ser dominados. Nem todo conflito político é, necessariamente, maquiaveliano, ainda que os aspectos gerais do republicanismo inevitavelmente tenham dívidas com Maquiavel. Desse modo, este artigo argumenta, contrariamente à maioria das interpretações, que Harrington é um partidário do conflito político, mas não um conflito de base maquiaveliana, e sim um conflito calcado no interesse. A diferença fundamental entre os dois autores nessa temática é: Maquiavel parte da ideia de que os homens têm vontades distintas e Harrington não. Porém, em ambos os casos, a realização de uma das vontades oblitera a vontade do oponente, 
de tal maneira que os resultados do conflito sejam fundamentalmente os mesmos para cada um dos pensadores.

Não se trata tão somente de uma reinterpretação da posição de Harrington sobre o conflito, ainda que em si mesmo já seja um tema de relevo. Porém, sobretudo, trata-se de se compreender uma importante transmissão de um assunto central do republicanismo que, com Harrington, teve suas bases teóricas profundamente modificadas. Quando o autor de The Commonwealth of Oceana atribui universalidade ao interesse e propõe sua institucionalização em duas casas legislativas, ele desloca a contrariedade dos humores divergentes para a uniformidade do comportamento humano (Hammersley, 2013, p. 369). Assim, o artigo argumenta não apenas que o conflito é peça chave do sistema de Harrington, mas também que é um modo mais homogêneo de pensar a natureza humana. A suposição de tal homogeneidade legou ao pensamento político posterior e, sobretudo, à conformação das instituições representativas dos séculos seguintes a premissa basilar de que os humanos devem ser tratados como iguais, de modo que a legitimidade política calcada em eleições seja o reflexo dessa igualdade.

\section{As facções e a igualdade}

O vocabulário do conflito empregado por Harrington (strife, sedition, tumultuous), em alguma medida, repete, como havia feito seu amigo e escritor Marchamon Nedham (2010), o de Maquiavel. Entretanto, a ambiguidade latente dos usos semânticos dificulta o estudo. Por exemplo, strife é uma palavra bastante comum em seus escritos, às vezes usada de modo pejorativo, como quando se refere à violência de Roma (Harrington, 1977, p. 180); às vezes é um modo de correção das instituições pela ação do povo, como no caso da antiga Israel (Harrington, 1977, pp. 263 e 731; cf. Boralevi, 2002; Remer, 2006). Já sedition e tumultuous são termos que fazem referência a uma falha institucional 
quando as instâncias representativas são incapazes de absorver as demandas do povo. Certamente, como Maquiavel, Harrington não advoga por um conflito externo às instituições, mas sua preocupação central reside na ascensão de poder de um grupo em detrimento de toda uma casa legislativa. "Os descontentamentos, sejam dos poucos ou dos muitos, derivam do que é, ou do que acham que seja, atrelado aos interesses de cada um deles" (Harrington, 1977, p. 424, tradução nossa), quando um grupo age nessas casas. $\mathrm{O}$ interesse mal controlado, ou não adequadamente institucionalizado, pode fazer com que parte dos muitos ou dos poucos subvertam a ordenação posta e deslizem para um modo violento de atendê-los (Somos, 2013, p. 85). Deriva-se daí o preciso uso harringtoniano de party.

Em seu sentido mais literal, party significa uma fatia da sociedade que, de modo contrário à natureza, consegue furar o bloqueio político-institucional a fim de canalizar 146 os interesses próprios. Explica-se também que é no seio de cada uma das casas legislativas que emergem os partidos, o que não deve ser confundindo, pois, com a totalidade da assembleia ou do senado (Harrington, 1977, p. 350). É justamente o embaraço entre party e senado ou assembleia que permite a interpretação de que Harrington é contrário ao conflito, uma vez que os partidos são causa de ações violentas e facciosas (Harrington, 1977, p. 749). Definitivamente, os poderes legislativos não são partidos, mas alvos dos partidos. Esse imbricado relacionamento entre os partidos e as casas legislativas faz com que a decisão a respeito da exclusão dos primeiros da república seja feita de modo bastante cauteloso, senão comedido: "Para um republicano, não tenho nada mais a dizer a não ser que, se ele excluir qualquer partido (any party), ele não está sendo verdadeiramente correto" (Harrington, 1977, p. 203, tradução nossa). Desse modo, deve-se controlar as causas do surgimento dos partidos de tal maneira que não encontrem espaço em 
nenhuma das duas casas legislativas, mas jamais deve-se persegui-los violentamente.

Harrington retoma, como de costume, o argumento de que em uma república igualitária, o povo não tem motivos para aspirar a nenhum dos três interesses existentes: poder, liberdade e riqueza. Cabe aqui destacar, coerentemente com seu autoelogio no começo de Oceana, que o ponto de inflexão para a república harringtoniana é a igualdade, elemento capaz de fundar e de sustentar a liberdade pelo divórcio entre interesse e poder (Carandini, 1972; Pocock, 1977, pp. 112-113). A realização do interesse popular, em seus três níveis e historicamente determinada, é condição suficiente para que sua representação na assembleia não caia em mãos facciosas (Scott, 2004, p. 300). Porém, ainda assim, é necessário que as instituições políticas sejam forjadas de modo tal que não seja possível a qualquer facção dominar a assembleia. Por isso, a liberdade é garantida pela igualdade na medida em que o interesse vislumbrado seja realizado e a facção obliterada antes de se efetivar.

A remoção das causas dos interesses facciosos pela igualdade permite que os efeitos sejam também controlados: "Portanto, o povo, em uma república igualitária, não tendo nenhum dos interesses que causam sedição, não pode ser sujeito de tal efeito" (Harrington, 1977, p. 425, grifos nossos, tradução nossa). A conclusão de Harrington em The prerrogative of popular government é a mesma daquela já descrita em Oceana: a separação entre interesse e concentração de poder na assembleia popular.

Observando na república proposta, o povo tem o poder, mas não pode ter tal interesse [capaz de dominar todo o legislativo], e, não tendo o povo tal interesse, nenhum partido pode ter tal poder, torna-se impossível que um partido venha a preponderar (overbalance) sobre o povo". (Harrington, 1977, p. 425, tradução nossa) 
E completa:

porque o poder ou efeito do povo grande é proporcionalmente maior do que o poder ou efeito do povo diminuto, e os poucos por esses meios não ganhariam mais do que ser o povo diminuto. Então, o povo, não sendo uma barreira para os ricos, e o poder sendo apenas causa da sedição, não poderia emergir sedição nessa república a partir da nobreza, que não tem esse interesse se tiver o poder, nem tem o poder se tiver o interesse. (Harrington, 1977, p. 426, tradução nossa)

A liberação do interesse pela igualdade de propriedade permite, ainda, a inserção na participação nos negócios públicos. Poderia parecer contraditório para um autor que sustenta parte de sua teoria no interesse buscar anulá-lo. Porém, o que Harrington faz é visar o controle das causas do 148 interesse faccioso, que levam à ação ilegítima e violenta, diferentemente do interesse individual, que leva ao desejo por liberdade, poder e propriedade (Carandini, 1972; Cohen, 1994, p. 196). Deve-se, desse modo, manejar esses interesses para que não acabem por se tornar aqueles. Além disso, é inevitável reconhecer que, tendo todos os cidadãos interesses, entram, de algum modo, em uma relação conflituosa.

As condições do conflito em uma república são, de fato, bastante limitadas. Harrington rejeita qualquer forma partidária ou facciosa, do mesmo modo que não deve, sob quaisquer circunstâncias, ser violento. O conflito se realiza na dimensão institucional da política de modo que rebata a natureza individual e distinta dos homens. Nesse sentido, os atributos do senado refletem aquilo que os senadores possuem a mais do que o povo: a sabedoria. Harrington é taxativo quanto ao fato de que se deve supor que todos os homens têm interesses, e dessa assertiva não exclui os senadores: "o senado não tem interesse distinto ou separado 
do interesse do povo" (Harrington, 1977, p. 724, tradução nossa). Assim, o conflito harringtoniano somente faz sentido se entendido à luz da desigualdade natural dos homens e da forma igualitária através da qual a política se mostra capaz de transformá-los (Capozzi, 1996, p. 63). Todavia, a igualdade artificial, criação da política, não deve limitar as vantagens da desigualdade natural dos homens; é preciso aproveitar aqueles mais sábios de algum modo. Em suma, todos os homens têm o mesmo interesse por riqueza e propriedade, mas não têm a mesma capacidade de realizá-lo, uns são mais aptos do que outros e essa é a evidência da qual ele precisa para atribuir sabedoria ao senado (Lurbe, 2007, p. 83).

Por isso, após discorrer sobre a relação conflitiva dos interesses em Roma, Harrington põe a questão da seguinte forma: "Não existe uma questão mais nobre ou útil em política do que aquela iniciada por Maquiavel: se haveria meios pelos quais a inimizade entre o senado e o povo de Roma poderia (might) ter sido removida" (Harrington, 1977, p. 272, tradução nossa). Claramente, a questão está posta no sexto capítulo do primeiro livro dos Discorsi. A conclusão de Maquiavel é "que não se pode nunca anular um inconveniente" (Machiavelli, 2010, p. 77, tradução nossa), portanto, está fora da alçada das possibilidades, dadas as condições romanas, de se findar com os tumultos. $\mathrm{O}$ "inconveniente necessário" (Machiavelli, 2010, p. 79, tradução nossa) levou Roma à expansão. A conclusão silenciosa de Harrington na mesma passagem apenas concorda com a do florentino: "E aquele que for erigir uma república contrariamente ao julgamento de Maquiavel está obrigado a dar as razões de sua empreitada" (Harrington, 1977, p. 273, tradução nossa). Depois de uma citação longuíssima do referido capítulo dos Discorsi, devidamente acomodada ao estudo das repúblicas expansivas e estáticas, Harrington atesta a necessidade de se debater a relação entre conflito e expansão. 
A questão posta por Maquiavel é de causas internas: se a inimizade que havia entre o senado e o povo de Roma deve ser removida. Para determinar a questão que ele colocou, eu preciso estabelecer outros princípios além dos dele. Para esse fim, afirmo que uma república internamente considerada é ou igual ou desigual. Uma república que é internamente igual não tem causa interna de comoção (commotion) e, portanto, não tem esse efeito senão vindo de fora. Uma república internamente desigual não tem causa interna de tranquilidade e, então, não tem esse efeito a não ser por desvio. (Harrington, 1977, p. 274-275, tradução nossa) ${ }^{1}$

A desigualdade provoca o conflito negativo, ao passo que a igualdade o impede (Harrington, 1977, p. 425). O fato de o interesse ser o mesmo para membros do senado (aristocratas) e da assembleia (povo) carrega consigo o imperativo da igualdade (Harrington, 1977, p. 277), a qual, nesse 150 ponto, justifica a crítica a Maquiavel (Downs, 1977, p. 72). "Por isso, Maquiavel, nesse e em outros lugares, tendo seus olhos na divisão entre famílias patrícias e plebeias como era em Roma, se equivocou nas ordenações dessa república, onde não havia essas coisas" (Harrington, 1977, p. 275, tradução nossa). Harrington não aceita que a desigualdade seja produtora de um "inconveniente necessário" (Harrington, 1977, p. 280, tradução nossa), antes, pretende demonstrar que é a igualdade - tanto em termos de cidadania calcada na propriedade quanto em termos de interesse (Pocock, 1989, p. 111) - o sustentáculo para o conflito ser necessário à república bem-ordenada. As causas do conflito interno, divergentes das de Maquiavel, remetidas na passagem acima, devem ser estudadas à luz das instituições políticas.

\footnotetext{
1 Repare-se que ocorre uma brusca mudança de vocabulário ao tratar, agora, de modo bem mais comedido o tema do conflito com relação a strife, tumultuous e sedition. Tal alteração na escolha dos termos permanece durante toda a análise diretamente relacionada a Maquiavel e, particularmente, seu entendimento de Roma.
} 


\section{Legislativo: a teoria do bolo}

Grande parte dos estudos a respeito de Harrington esforça-se por apresentar uma perspectiva harmônica, conciliatória e consensual da política ou, pelo menos, oposta ao conflito (Arienzo, 2009, p. 220; Barros, 2015, p. 438; Blitzer, 1970, p. 296; Boralevi, 2011, p. 119; Cambiano, 2000, p. 242; Capozzi, 1996, p. 38; Davis, 1981, p. 694; Downs, 1977, p. 69; Fukuda, 1997, p. 117; Geuna, 1998, p. 117; Geuna, 2013, p. 26; Pedullà, 2011, pp. 53-60; Rahe, 2008, p. 339; Remer, 1995, p. 536; Scott, 2004, p. 118; Shklar, 1959, p. 686; Sullivan, 2004, p. 18; Worden, 1994, p. 98; Zagorin, 1997, p. 138), apesar das exceções sempre comedidas e reticentes (Barducci, 2013, p. 67; Macpherson, 1963, p. 83; New, 1963, p. 78; RusselSmith, 1914, p. 53; Strumia, 1991, p. 57; Tahvainen, 2012, p. 179). A utilização de termos e recursos argumentativos fortemente vinculados ao direito natural (law of nature, natural right, consent etc.) sugere uma certa dívida ao pensamento de autores como Grotius e Hobbes (Capozzi, 1996, p. 21) e, portanto, inevitavelmente contrário ao conflito.

Todavia, Harrington não sustenta seus argumentos em uma universalidade de paixões humanas à moda do jusnaturalismo. Pelo contrário, ao tratar das capacidades humanas, não nega que os homens são, por natureza, diferentes (cf. Capozzi, 1996, p. 37). A arbitrariedade da proporção dessa diferença, seis homens em vinte são os mais inteligentes, reconhecida por ele próprio como uma proposição aleatória, não apenas o distancia de uma teoria da natureza humana homogênea em termos de capacidade, como também impede a uniformidade das realizações políticas. A consequência pública da distinção natural dos homens confirma que o universo político não pode negá-la (Fink, 1962, p. 55), ou seja, ainda que a república deva ser igualitária, deve também considerar as idiossincrasias da estupidez e da sabedoria humanas. Assim, o substrato heterogêneo dos homens configura a necessidade de instituições políticas igualmente heterogêneas, a fim de 
que o resultado seja a igualdade (Davis, 2007, pp. 229-230; Pocock, 1977, pp. 181-182). O argumento caminha substancialmente em direção ao governo misto, no sentido rigorosamente oposto ao governo hobbesiano pautado em homogeneidades. A chave para a compreensão da diversidade natural dos homens e seu rebatimento nas instituições políticas é o poder legislativo de Oceana.

A divisão do legislativo em duas casas não apenas reparte o poder, mas também suas funções (Cambiano, 2000, p. 237). O senado possui a atribuição natural de propor as leis, a assembleia, a de escolhê-las (cf. Blitzer, 1970, p. 150). O argumento se inicia com uma suposta simplicidade. Duas meninas possuem um bolo, ao reparti-lo, uma diz à outra: “'Divide', diz uma à outra, 'e eu vou escolher, ou deixe-me dividir e você escolhe" (Harrington, 1977, p. 172, tradução nossa). Aqui, pressupõe-se que exista uma contrariedade nas vontades sob um mesmo objeto em disputa, ambas desejam a maior parte 152 do bolo, por interesse próprio. ${ }^{2}$ Não obstante a dimensão auto interessada do comportamento humano (Russel-Smith, 1914, p. 32), possível recepção de Hobbes, essa característica não é capaz de produzir consenso. Inverte-se a assertiva hobbesiana de que igualdade nas paixões produz consenso político. $\mathrm{Na}$ verdade, a igualdade dos interesses produz, em Harrington, conflito. É verdade que, antes do estabelecimento do contrato social em Hobbes, essa igualdade natural produz conflito e imprevisibilidade e pode, inclusive, levar à guerra. ${ }^{3}$ É justamente por isso que o contrato se faz necessário. Nesse

\footnotetext{
$2 \mathrm{O}$ fato de Harrington unir o interesse na riqueza e no poder confirma que o objeto sob disputa é o mesmo: "Mas eles estariam ansiosos depois de mais [riqueza]. Por quê? Porque são ricos ou pobres. Todos os magistrados são responsáveis perante a assembleia popular; e assim, sem aquisição de poder, não posso imaginar por qual caminho eles devem se voltar para a aquisição de riquezas" (Harrington, 1977, p. 792, tradução nossa).

3 Para sermos precisos, é necessário pontuar que, em estado de natureza, os homens não são iguais, porém, não são desiguais ao ponto de que se estabeleça o domínio de um sobre outro.
} 
sentido, a relativa igualdade natural dos homens leva a uma desigualdade artificial consensualmente. No ponto de inflexão, da natureza diversa para a artificialidade igualitária, Harrington se distancia mais do que nunca de Hobbes e o critica justamente nesse ponto (Harrington, 1977, p. 423). Diferentemente de Hobbes, Harrington (1977, p. 375) foca sua análise na igualdade dos interesses humanos, ou seja, o fato de os homens possuírem os mesmos interesses não significa que a artificialidade seja a necessária desigualdade.

Nessa altura da argumentação, lembramos apenas a dimensão natural com que Maquiavel reconhece as idiossincrasias individuais através dos humores (umori). A consequência de tal diversidade insere-se igualmente em conteúdos diversos de humores: há aqueles que desejam dominar e os que desejam não ser dominados. A impossibilidade de que um dos humores seja realizado plenamente sem que o outro seja destruído lança à questão um ponto de difícil solução. O objeto sob disputa recai, necessariamente, sobre a dominação e, a partir daí, a política pode ser vista como conflito (Pedullà, 2011, p. 94). Por isso, o conflito maquiaveliano é baseado na desigualdade nata dos humores.

O desenvolvimento argumentativo de Maquiavel, dos humores ao Estado como unidade incidente dos tumultos, auxilia-nos no entendimento harringtoniano do conflito. Assim como a virtù é atributo intransferível, a capacidade de obtenção de propriedade é, em Harrington, também atributo individual e nato. A generalização da premissa de que todos possuem alguma capacidade de obter propriedade não confere igualdade, pois cada um possui uma capacidade própria. Jonathan Scott (1993) e Michel Downs (1977, p. 115) observam nessa característica da condição humana uma antecipação da função da propriedade na teoria de Locke, o que apontaria também para uma proximidade com o direito natural e o liberalismo clássico. Russell-Smith (1914, pp. 139-140) reconhece a presença 
marcante da propriedade em ambos, embora não afirme uma necessária correlação entre o destaque da propriedade e o liberalismo. Ocorre que a capacidade natural de obter propriedade não leva a uma realização igual dessa capacidade. Em outras palavras, se em Maquiavel a diversidade humana enseja humores diferentes, em Harrington, a diversidade de capacidade de obtenção de propriedade não leva a uma diferença de interesses. Todos têm o mesmo interesse de obter propriedade, mas cada um possui individualmente uma determinada capacidade de obtê-la. ${ }^{4} \mathrm{O}$ objeto harringtoniano sob disputa, a propriedade, revela um distanciamento entre a capacidade de obter propriedade e a igualdade do desejo de obter sempre mais propriedade, gerando frustrações. Essa naturalidade com que os autores tratam os desejos humanos, seja de dominar, seja de adquirir propriedade, relaciona-se diferentemente em cada um deles. Os humores em Maquiavel produzem um rebatimento 154 distinto, os que desejam dominar (grandes) e os que desejam não ser dominados (povo). Já em Harrington, a natural capacidade de os homens obterem propriedade não impede que o desejo por mais propriedade exista sempre (cf. Rahe, 2008, pp. 339-341). A igualdade dos interesses em contraste com a desigualdade dos humores revela, segundo Harrington, o "equívoco" de Maquiavel. ${ }^{5}$

\footnotetext{
4 Afirmamos acima que, para Harrington, o interesse se apresenta como desejo de liberdade, poder e propriedade. Tratamos aqui apenas da propriedade porque, uma vez conquistada, liberdade e poder são apenas decorrências dela, como o próprio autor reconhece.

${ }^{5}$ Não é raro o emprego de humor por Harrington, como era bem comum na Inglaterra de seu tempo. O que parece significativo é que, em uma única passagem, claramente, coloca-o como substitutivo de interesse justamente ao comentar as contendas parciais das cidades: "os humores (humours) ou interesses (interest) dos partidos predominantes sustentam-se nacionalmente, e aqueles que os visam jamais podem visar a nação, nem aqueles que visam a nação podem visar os partidos" (Harrington, 1977, p. 590, tradução nossa). Por isso, o suposto "equívoco" de Maquiavel é justificado pelo fato de todos terem o mesmo interesse. O uso equivalente de humor e de interesse na passagem acima confirma que, para Harrington, essa diversidade não existe: seja humor, seja interesse, todos os homens têm os mesmos desejos.
} 
Fukuda (1997, pp. 41-45, 72 e 88) e Cotton (1981) explicaram muito bem que Harrington divide com Hobbes a noção de que a igualdade natural, em Hobbes no estado de natureza, em Harrington com relação às meninas, produz insegurança ou guerra civil. Não obstante Hobbes tratar de paixões e Harrington de interesses, ou, quando muito, de ânimos e humores, é apenas na criação de artificialidades, o corpo artificial ou as casas legislativas, que essa igualdade evita a violência (Cengiarotti, 1988, p. 89; Sullivan, 2004, p. 167; Tahvainen, 2012, pp. 170-171). Em Maquiavel, por outro lado, é a diferença no conteúdo de cada um dos humores que implica no conflito político e na parcial realização de cada um deles para a produção de ordenamentos, leis, liberdade e grandeza.

Harrington aprofunda tal dicotomia quando insere a igualdade no desejo de obtenção de mais propriedade em contraste com a impossibilidade de realização plena. Em suma, o que em Maquiavel era diferente, por atributo intrínseco (humores), em Harrington se torna igual (interesse) também de modo nato. Nesse sentido, o erro de Maquiavel consiste em não ter identificado, como bem fez Hobbes, que os ânimos humanos são iguais. Por isso, a intensidade com que Harrington trata da diferença entre as funções legislativas é mais profunda do que aquela que fez Maquiavel, se é que o florentino o fez. Mais precisamente, o senado e os tribunos da plebe se relacionam mais diretamente com a tradição do governo misto, o que também é verdade para Harrington, mas com um argumento a mais. Dado que os interesses são os mesmos em todos os homens, mas alguns possuem sabedoria/capacidade para adquirir mais propriedade (Hammersley, 2013, p. 364; Somos, 2013, p. 87), é necessário que as casas legislativas atuem com funções absolutamente dessemelhantes (Lurbe, 2007, p. 81) de modo que absorvam a diversidade natural dos homens, mas sem que, com isso, eles produzam facções (Harrington, 1977, p. 172). 
A teoria do bolo autoriza uma leitura conflituosa não apenas pela igualdade de interesses nos indivíduos, mas também por sua manutenção a partir da produção das instituições políticas. "Dividir e escolher, em linguagem republicana, é debater e resolver" (Harrington, 1977, p. 174, tradução nossa). A relação conflituosa das meninas passa a ser uma relação igualmente conflituosa na política, mas com uma distinção importante. As meninas possuíam, por pressuposto, as mesmas habilidades e interesses, portanto, comportavam relações equitativas de conflito, bem aos moldes hobbesianos. Já as casas legislativas absorvem a diversidade humana, o senado deve apenas propor as leis e a assembleia apenas votá-las.

Mas aqueles que são capazes desse tipo de divisão ou debate são poucos entre muitos que, quando as coisas são assim divididas e debatidas, os muitos são aptos à escolha, o que na linguagem republicana é resolver [...] Esses seis, inclinados ao discurso dos negócios, dando seu julgamento a pessoas ou coisas, através apenas de mera conversação, descobrirão suas habilidades, que devem ser ouvidas e consideradas pelos quatorze. (Harrington, 1977, p. 416, tradução nossa)

Por causa da sabedoria do senado, ele é capaz de debater uma proposta aceitável pela assembleia. Isso não significa que o povo não tenha capacidade de debater, mas que não a tem de modo que seja direcionada ao coletivo da república. Em outros termos, o povo é incapaz de propor não porque seja incapaz do exercício de cidadania (Worden, 1994, p. 104), mas porque é incapaz de antecipar uma proposta que seja legitimada por toda a república, e essa antecipação é o que caracteriza a sabedoria do senado (Harrington, 1977, p. 281; cf. Tahvainen, 2012, p. 166). É importante notar que não há qualquer sobreposição de funções, aqueles que propõem não podem votar, os que votam não podem propor. $\mathrm{O}$ rigor da medida se deve à 
prevenção de cumprimento de apenas uma das ações como modo de sustentar a igualdade entre as casas e os grupos sociais. Desse modo, as leis devem passar pelo crivo das melhores opções para, em seguida, passar pela votação. O pressuposto é de que o senado não proporia uma lei que não lhe fosse favorável, mas também não faria uma proposta que fosse desfavorável ao povo, pois, se assim for, a assembleia não aprovaria (Harrington, 1977, p. 596). O resultado, portanto, é que as leis são favoráveis para ambos: "se o legislador ou o senado dividir corretamente, o povo pode ter certeza de fazer a escolha" (Harrington, 1977, p. 721, tradução nossa). Da mesma maneira, a racionalidade de cada menina faz com que aquela que corta o bolo o faça de modo equitativo, com o fito de garantir a si mesma a maior fatia possível. Caso o bolo não seja cortado ao meio, aquela que cortou não terá a maior parte, pois será escolhida pela outra. Essa situação descreve um erro de racionalidade e, portanto, de interesse, já que para ele interesse e razão são a mesma coisa (Harrington, 1977, p. 171; cf. Lurbe, 2007, p. 80). A hipótese de Harrington é de que cada menina conhece seu interesse próprio assim como cada casa legislativa conhece o seu, mesmo que não necessariamente conheça o do adversário, particularmente no caso da assembleia.

Em Maquiavel, na dedicatória de $O$ Príncipe, a metáfora dos lugares baixo e alto mostra aspectos distintos da percepção da política em que o adversário conhece melhor seu oponente do que a si mesmo, embora reaja melhor com seu próprio humor. Aplicando a máxima a Harrington, significa que mesmo que uma menina reconheça melhor a posição da outra, a reação é sempre em direção ao interesse próprio, porque interesse é, por definição, genuíno e não pode ser burlado: "Senhor, se um homem não sabe o que é seu interesse, quem saberia?” (Harrington, 1977, p. 719, tradução nossa; cf. Polin, 1952, p. 27). Independentemente se a menina que corta pressupuser que a outra possua a mesma racionalidade que 
a sua (interesse próprio), a melhor jogada é contar que sim. Portanto, é ato racional, porque interessado, dividir o bolo ao meio. "O povo, em quem reside o poder de votar a lei, jamais usaria o poder contra si mesmo, de modo que as propostas do senado devem expressar tanto os interesses do povo como os seus próprios, de outro modo, a lei não seria aprovada" (Zagorin, 1997, p. 140, tradução nossa). Assim, é racional, porque auto interessado, que o senado proponha apenas leis que sejam aprovadas pela assembleia, produzindo, pois, igualdade.

\section{Natural Aristocracy e funções legislativas}

Fica ainda uma questão na relação entre as meninas e as instituições. Nas relações privadas da cozinha, não importa quem corta e quem escolhe, mas importa a ordem em que essas coisas acontecem.

Mas, embora a posição de dividir e escolher seja comutável entre as meninas, não é indiferente na distribuição da república, porque dividir é separar uma coisa da outra, uma razão, um interesse ou uma consideração. Aqueles que podem assim discernir em questões privadas são chamados discretos (discreet), mas aqueles que podem fazê-lo sobre o público são prudentes (prudent); e o caminho para esse tipo de divisão, em linguagem republicana, é debater. (Harrington, 1977, p. 416, tradução nossa)

A narrativa de Harrington não impede que se suponha uma situação em que uma parte do bolo seja escolhida antes mesmo de ser cortada. ${ }^{6}$ No entanto, essa situação não incorre em qualquer modo de racionalidade, pois fica claro que o corte será em função da escolha. Por isso, deve ser em sentido inverso, a escolha deve vir depois do corte, para que

${ }^{6}$ A constante retomada da metáfora e seu tensionamento ao máximo por Harrington autoriza-nos a colocá-la nessa perspectiva comparativa com o legislativo. 
ambas utilizem sua racionalidade e produzam, mesmo sem intimamente os desejar, resultados equitativos. Por isso também, necessariamente, a ordem deve ser cortar para depois escolher. Disso resulta que o desencadeamento lógico das ações necessariamente deve ser acompanhado de uma informação particular. Quem corta, durante a ação, deve saber que a escolha será feita por outra pessoa, de modo que o tamanho do corte seja considerado. "O senado não pode fazer nada além de propor para o povo, não é possível para ele concordar com nada que possa ser proposto sem debate, nem pode qualquer debate tender a qualquer concordância senão conduzido pela força da razão" (Harrington, 1977, p. 741, tradução nossa). Ou ainda: "Mas o resultado deve necessariamente passar por um debate que o precede; vendo que um homem, muito menos que uma assembleia, não resolve nada sem considerações, motivos e razões, que devem ser debatidos de modo ordenado e maduro" (Harrington, 1977, p. 790, tradução nossa). ${ }^{7}$

Nos termos do legislativo, fica ainda mais evidente. Não se poderia votar uma lei que não se conhece, a priori, qual seja, a não ser que o senado receba autorização para aprovar qualquer lei, o que tornaria a república uma oligarquia. Do mesmo modo, o senado deve saber de antemão que a assembleia votará sua proposta. Nesse sentido, o conflito entre as casas legislativas se faz antes mesmo do momento de escolha das leis, pois já está inserido dentro da sabedoria do senado, do mesmo modo que o conflito maquiaveliano existe antes mesmo das instituições, visto que os humores existem

\footnotetext{
7 Possivelmente, a lógica já descrita em Oceana, mas não expressa, teve de ser explicitada nos escritos posteriores devido às críticas recebidas. Do mesmo modo, em 1660, um de seus últimos textos chega a aceitar a existência de um rei (Harrington, 1977 , p. 825), mas apenas pelo fato de ser proposto pelo senado e aceito pela assembleia. $O$ contexto posto da restauração daquele ano, inclusive, fez com que as propostas iniciais, tão importantes nos primeiros escritos, a respeito da lei agrária fossem deixadas de lado, o que já se evidenciava nos textos de 1659. Contudo, o debate e a resolução permanecem intactos durante toda a obra, o que os coloca, pelo contexto ou pela força teórica, em uma posição privilegiada.
} 
antes da criação do senado e dos tribunos. Isso intensifica a distinção com as meninas, porque a sabedoria distintiva do senado em relação à assembleia permite que seja capaz de antecipar, pela sabedoria, o comportamento da assembleia e, portanto, propor a lei que julgar aceitável por ela.

O pressuposto igualitário das meninas não considera a inserção da desigualdade de capacidades vigente no senado, que ele nomeia natural aristocracy, considera apenas a igualdade do conteúdo do interesse. Isso levou Harrington a alocar cada função, propor e escolher, em cada casa específica, e obliterar qualquer sobreposição. Uma interpretação aristocrática de Harrington poderia colocá-lo na perspectiva rígida da naturalização da desigualdade (Barros, 2015, p. 424). De fato, quanto à sabedoria/capacidade, ele o faz, mas isso não imputa rigidez política. Pelo contrário, diferentemente de Maquiavel, que parte da diversidade dos humores, Harrington parte da igualdade dos interesses e é essa igualdade que deve ser refle-

160 tida no legislativo (Downs, 1977, pp. 64-65). Com isso, uma leitura mais democrática de Harrington afirma que a diferença de funções existe para garantir a igualdade de interesses inconciliáveis. Em outras palavras, propor e escolher é a única maneira de garantir que a superioridade natural de alguns homens não implique em superioridade política. Em certo sentido, Harrington pretende construir um artifício político que limite ao máximo as distorções oriundas da natureza.

\section{Parcialidade e emulação}

Além do famoso capítulo quatro do primeiro livro dos Discorsi, é no capítulo nove de O Príncipe que Maquiavel apresenta com mais clareza o resultado dos conflitos: licença, principado ou liberdade. A república e o principado civil são os dois únicos regimes que sustentam a tensão conflituosa de modo não violento, ainda que não o façam da mesma maneira. $\mathrm{O}$ argumento, especificamente maquiaveliano, reside, pois, no fato de que cada uma das vontades se realiza 
apenas em parte, isto é, em parte os grandi dominam e em parte o popolo não se deixa dominar. Quando Harrington afirma que o senado deve propor para que a assembleia escolha, não está dizendo nada substancialmente diferente de quando Maquiavel afirma a realização parcial de cada um dos humores. Claro que, para Harrington, como vimos, não se trata de humores, mas de interesses. Nenhuma das duas casas realiza plenamente seu interesse próprio. Não obstante a justificativa do interesse ser diversa da do humor, o fato é que apenas parcialmente eles se realizam. O senado, em parte, consuma seu interesse, porque deve fazer concessões à assembleia se quiser ter suas propostas aprovadas. A assembleia, em parte, tem seus interesses atendidos, porque o senado apresentou leis favoráveis a ele próprio que possam ser aceitas por ela. Assim, é a parcialidade da realização que insere o conflito na teoria de Harrington e faz dele um exímio maquiaveliano.

Acima, apontamos que o operador do conflito em Maquiavel é a distinção dos humores e que, em Harrington, é a igualdade do interesse. Como muitos comentadores afirmam, o caráter especificamente maquiaveliano reside na diversidade humana realizada binariamente na política entre aqueles que desejam dominar e os que desejam não ser dominados, se positivado o humor negativo do povo, conforma-se, desse modo, um oximoro (Adverse, 2007). O mesmo não se aplica a Harrington, uma vez que não há tal diferença nos interesses, o que o levou a inserir a diferença de funções nas casas legislativas. ${ }^{8}$ A calibragem feita da passagem dos humores para o interesse pôde

\footnotetext{
8 Barber (2004) conduz uma interessante análise a partir de uma definição de republicanismo moderno como um oximoro em si mesmo. $\mathrm{O}$ argumento pretende refletir sobre a possibilidade de se inserir virtude cívica em um universo que já avançara demais na aceitação geral de sua impossibilidade. É bem verdade que não se trata aqui do tema discutido por Adverse (2007). Porém, uma vez que Barber reconhece o pioneirismo de Maquiavel, sobretudo em sua discussão do conflito, parece frutífera a comparação de uma vontade negativa que deve ser positivada com a dependência republicana de atitudes não republicanas.
} 
permitir a separação de funções. Em ambos os casos, há uma homogeneidade - na função legislativa (Maquiavel) ou no interesse (Harrington) - e uma heterogeneidade no humor (Maquiavel) ou na função legislativa (Harrington) -, o que muda, entretanto, é a ordem daquilo que é homogêneo ou heterogêneo, justificado, cada um a seu modo, pelo comportamento humano. Importa destacar que é na tensão entre o que é homogêneo e o que é heterogêneo que emerge o equilíbrio político. Não seria, assim, despropositado afirmar que o conflito harringtoniano é fundamentalmente diferente do conflito maquiaveliano se, e somente se, for definido o conflito maquiaveliano pela distinção dos humores (cf. Pocock, 1977, p. 116), como de fato deve ser feito. Nesse sentido, não se pode discordar de todos aqueles que afirmam que Harrington posiciona-se contrariamente ao elogio do conflito por Maquiavel, o que não significa afirmar que haja uma crítica inerente a qualquer forma de 162 conflito ou que ele não reconheça sua inevitabilidade.

O republicanismo que recepciona Cícero, particularmente aquele do humanismo cívico e do jusnaturalismo, encontra nesse autor as propriedades necessárias de uma república bem ordenada de tal modo que os conflitos sejam totalmente afastados da república (Geuna, 1998). Fincados no bem comum e/ou na lei da natureza, esse republicanismo se assenta no governo misto pela complementariedade entre os poderes em sua divisão funcional (Worden, 1994, pp. 90-95). Assim, justificam uma virtude moral por algo que seja transcendente à condição humana cuja realização se faz pela bondade, utilidade e, sobretudo, justiça do governo (Pedullà, 2011). Fosse Harrington partícipe desse grupo, como querem Capozzi (1996, p. 39), Lurbe (2007) e Scott (1993), não haveria sentido na completa divisão de funções entre o senado e a assembleia, visto que uma não serve apenas para barrar o avanço interesseiro da outra, mas também para realizar parcialmente seus interesses. 
A tradição ciceroniana, ao negar a oposição entre interesse/utilidade pública e privada, reitera a realização do bem comum pela via do consenso, isto é, de algum modo por desígnio divino, lei ou direito da natureza, ou racionalidade individual -, todos os cidadãos concordam com o justo e o correto do bom governo. $\mathrm{O}$ fato de haver realizações apenas parciais dos interesses na teoria de Harrington o afasta desse republicanismo consensual. Porém, por não julgar que há homens dispostos a dominar e outros dispostos a não serem dominados, também, nesse caso, rejeita a teoria de Maquiavel em sua totalidade. Não se trata aqui de apenas uma possível "originalidade" da contribuição harringtoniana para o republicanismo, mas do fato de ele absorver o realismo político calcado no interesse de tal modo que arregimente adequadamente as instituições (cf. Lurbe, 2007, p. 100; Schklar, 1980, p. 105; Worden, 1994, p. 85). Jamais, para Harrington, haverá consenso entre as meninas ou o legislativo, mas, se bem ordenada, a república é capaz de estabelecer legitimidade política através da igualdade. Existe uma forte evidência de que Harrington tinha consciência de sua dívida com Maquiavel nesse ponto. As consequências do conflito podem ser lidas a partir de um desencadeamento de causas e efeitos.

Onde, em primeiro lugar, a culpa que ele [Hobbes] atribui aos autores pagãos recai sobre esse sentido das Escrituras, e enquanto ele diz serem jovens ou homens incuráveis aqueles que têm opiniões semelhantes, deve-se observar que Maquiavel, o único que mantém a prudência antiga, é, para a razão sólida de Hobbes, um moçoilo que acabara de ler Lívio. E é tão sólida sua razão que admite a prosperidade das grandes repúblicas antigas, o que é suficiente para findar a controvérsia, pois tal efeito deve ter uma causa adequada. Para escapar da controvérsia, ele insinua que não é mais que a emulação de determinados homens, como se uma grande 
emulação pudesse ser gerada sem grande virtude, tão grande virtude sem a melhor educação, a melhor educação sem as melhores leis, ou as melhores leis senão pela excelência política. (Harrington, 1977, p. 178, tradução nossa)

Não se pode com razão chamar de desordenada uma república dessas, onde há tantos exemplos de virtude, porque os bons exemplos nascem da boa educação, a boa educação das boas leis, as boas leis daqueles tumultos que muitos condenam imponderadamente. (Machiavelli, 2010, p. 71, tradução nossa)

A passagem de Harrington é quase uma reprodução textual da de Maquiavel. ${ }^{9}$ Como é bem característico de sua escrita, Harrington apresenta relações de causa e efeito entre os conceitos apresentados. Afirma que a emulação se une à virtude, a virtude à melhor educação, essa se origina 164 nas melhores leis e as melhores leis da excelência política. Maquiavel refere-se aos exemplos de virtude, os bons exemplos advêm da boa educação, a boa educação das boas leis e essas dos tumultos. Seguindo de perto o texto, identificam-se duas diferenças. Maquiavel utiliza adjetivos positivos (buona educazione, buone leggi), enquanto Harrington utiliza adjetivos superlativos (the best education, the best laws). Com o cuidado que sabemos que Harrington tem com as palavras empregadas do qual ele estava consciente (cf. Harrington, 1977, pp. 558 e 616; Ostrensky, 2011, p. 174), isso não significa outra coisa senão a radicalização do argumento de Maquiavel da passagem de um termo para outro (cf. Rahe, 2008, p. 326). Para Harrington, não basta que os termos sejam bons em si mesmos, mas devem ser os melhores, o que aponta para uma restrição, uma singularidade, na república

\footnotetext{
9 Confira ainda uma reprodução semelhante em Oceana (p. 303) e Pocock (2003, p. 195).
} 
bem ordenada, permitindo, inclusive, sua imortalidade, como querem Downs (1977, p. 95) e Worden (1994, p. 88).

A segunda diferença é mais significativa para nossa argumentação. A tradução das palavras do secretário florentino não ocorre apenas em um único caso das relações de causa e efeito: o último. Para Maquiavel, aquilo que impulsiona as boas leis, seguidas da educação e da virtude, é o tumulto, para Harrington, a excelência política (cf. Wiemann, 2013, pp. 45-46). Assim, duas interpretações são possíveis para justificar a substituição. Primeiramente, Harrington rejeita o conflito (tumulto) e, em seu lugar, coloca a excelência política (Bignotto, 1994, p. 182), o que significaria que excelência política é diferente de conflito. Segunda possibilidade, Harrington equivale tumulto à excelência política e, com isso, fecha a equiparação das causas e efeitos seguindo Maquiavel passo a passo. Assumindo sua aversão à palavra tumulto, como vimos acima, é plausível supor que a segunda interpretação é mais compatível com seu sistema teórico. Porém, tendo em vista a ambiguidade com a qual ele utiliza os termos para designar o conflito (strife, por exemplo) e, à luz de seu rigor não apenas quanto ao vocabulário (Harrington, 1977, pp. 460-461), mas também quanto, sobretudo, à sua constante preocupação com as explicações a partir de relações entre causa e efeito, dadas as causas, os efeitos não poderiam ser outros. "Um efeito universal demonstra uma causa universal" (Harrington, 1977, p. 765, tradução nossa). Assim, o desencadeamento lógico das proposições não pode concluir nada diferente de que a excelência política seja equivalente ao tumulto, uma vez que ele próprio aceita toda a cadeia de eventos descrita nos Discorsi.

Há que se concluir, portanto, que a substituição do tumulto pela excelência política, simultaneamente, aceita e rejeita o conflito maquiaveliano. Em parte, Harrington aceita o conflito elogiado por Maquiavel, porque ele é a origem das boas leis, da boa educação e dos bons exemplos. 
Em parte, Harrington rejeita o conflito maquiaveliano por não se tratar de dois humores diversos. Em suma, a excelência política depende de que se compreenda que os conflitos na república se voltem para os interesses. Por isso, é necessário compreender as causas do conflito harringtoniano.

\section{As causas do conflito}

Mobilizando Aristóteles contra Hobbes, Harrington cita uma passagem da Política (1302b) que vale a pena ser reproduzida:

Riqueza imoderada (immoderate wealth), como quando um homem ou poucos têm tão mais posses (greater possessions) do que a igualdade ou do que a estrutura da comunidade política (commonwealth), é uma condição de sedição (sedition), o que acaba em grande medida em uma monarquia. E, por esta razão, o ostracismo foi gerado em diversos lugares, como em Argos e Atenas. Contudo, seria melhor prevenir o crescimento desde o começo do que quando ele chegasse ao auge, a fim de haver um remédio para tamanho mal. (Harrington, 1977, p. 166, tradução nossa)

Como é sabido, e os próprios textos confirmam, Harrington dominava a língua grega e muito provavelmente, como era comum entre os eruditos de seu tempo, lia o estagirita no original e ele próprio fazia as traduções (cf. Toland, 1700, p. xi). Cabe uma reflexão sobre a versão inglesa adotada pelo autor de Oceana. Para Harrington, immoderate wealth (dýnamis em Aristóteles) e greater possessions (meizhon dýnamis em Aristóteles) assumem um significado eminentemente econômico, bem característico de riqueza e propriedade. "Sua economia era oikonomika no sentido grego" (Pocock, 1977, p. 63, tradução nossa.; cf. Capozzi, 1996, p. 83; Strumia, 1991, p. 28). Mesmo que essa tradução seja legítima para os termos de Aristóteles, ainda que pouco 
usual, é interessante frisar o esforço do autor de Oceana em correlacionar a propriedade com o poder político. De fato, a opção por wealth, ao invés de riches, como anteriormente no texto havia preferido para tratar os bens da fortuna, indica uma determinada cautela, porque wealth pode assumir um significado mais amplo do que apenas riqueza (cf. Ostrensky, 2011, p. 175).

$\mathrm{O}$ argumento de Harrington, em sua resposta a Hobbes, se faz destacando a riqueza como causa de sedições (stásis) ${ }^{10}$ (cf. Capozzi, 1996, p. 103; Pezzato, 2005, p. 226). Diferentemente do que Hobbes havia argumentado, que o contrato é capaz de garantir a ordem por ser uma transferência incondicional, Harrington afirma que a condição de empoderamento não é senão garantida pela propriedade, por isso, o contrato é ineficaz e inócuo (Gough, 1930, p. 397). Isso coloca-o em uma posição, não de omissão do momento contratual, como afirma Russel-Smith (1914, p. 18), mas de oposição teórica à própria plausibilidade de um contrato social. $\mathrm{O}$ ponto que Harrington pretende destacar de Aristóteles o diferencia tanto de Hobbes quanto de Maquiavel. Com relação ao primeiro, o problema reside na teoria do contrato (Capozzi, 1996, p. 159; Cotton, 1979 e 1981), com o segundo, como vimos, na origem explicativa do conflito. O pacto é ineficaz ou inócuo, e, portanto, não pode ser mobilizado como uma categoria explicativa, pois a soberania é uma consequência da distribuição de propriedade (Harrington, 1977, p. 409; cf. Raab, 1965, p. 196). Propriedade essa que enseja simultaneamente os motivos para o conflito. De acordo com a interpretação harringtoniana de Maquiavel, o florentino não leu Aristóteles corretamente:

\footnotetext{
${ }^{10}$ Nedham (2010, pp. 58-59) afirma que as causas dos tumultos são a vontade de poder, a vontade de liberdade e a opressão. É possível que Harrington tenha sintetizado esses termos a partir da propriedade, que será inserida por Nedham (2010, p. 61) na desmesura popular dos tumultos.
} 
Maquiavel, obtusa e perigosamente, perdeu a oportunidade de perceber em sua completude que se uma república for atormentada (galled) pela gentry, é porque ela prepondera (overbalance). Ele fala da gentry como hostil ao governo popular e do governo popular como hostil à gentry, e faz crer que o povo em si mesmo é tão furibundo com ela que se encontrasse um cavalheiro o mataria, e que jamais na Suíça um nobre está a salvo, apenas pela sua honra. (Harrington, 1977, p. 166, tradução nossa)

O erro de Maquiavel consiste em não perceber que o motivo da tormenta (galled) das repúblicas é a preponderância (overbalance) da gentry. "Em quase todos os lugares onde Harrington corrige ou discorda de Maquiavel, a base de sua crítica é que ele falhou explicitamente em ver o princípio do equilíbrio como uma chave necessária para um entendimento completo da situação" (Raab, 1965, p. 190, tradução 168 nossa). Nesse ponto, a leitura harringtoniana é radical: a hostilidade entre povo e nobreza descamba em assassinatos e guerra civil (Barducci, 2013, p. 68). "Nessa falha em reconhecer a relação entre propriedade e poder, Harrington acredita que Maquiavel falhou como observador e teórico" (Downs, 1977, p. 29, tradução nossa). A crítica desferida a Maquiavel aponta para causas distintas daquelas descritas pelo secretário de Florença. Já na passagem acima citada, vê-se uma causa negligenciada, até então, pelas outras interpretações de Maquiavel: o balance. O que Harrington afirma é que o motivo do conflito é a correlação de riquezas do povo e dos nobres, que pode ou não se precipitar em violência.

Quando ocorrem assassinatos e guerras civis é devido à preponderância de propriedade (Polin, 1952, pp. 28-29) . O esquema teórico, portanto, se passa, primeiro, pela explicação de que é o equilíbrio (balance) a causa do conflito e a preponderância (overbalance) causa da violência no conflito. Devido a essa distinção, sutil, encontra-se Harrington 
pressionado a reconhecer sua dívida para com o florentino: "Mas o equilíbrio como eu estabeleci, embora não observado por Maquiavel, é o que o interpreta e o que ele confirma pelos seus julgamentos em muitos casos, assim como nesse caso [da propriedade]" (Harrington, 1977, p. 166, tradução nossa). Maquiavel não expôs, mas a teoria do balance está submetida em seu texto. Conclui Harrington do seguinte modo: "Portanto, nesse ponto eu concordo com Maquiavel que a nobreza ou a gentry, preponderando no governo popular, é a maior desgraça e a destruição da república" (Harrington, 1977, pp. 166-167, tradução nossa).

Entre a crítica e o elogio, Harrington procura no próprio texto do florentino seu fundamento de balance para a explicação dos conflitos. De fato, encontra-o e traduz: "[...] fazendo-os senhores ou nobres, não em nome, mas de fato, através do enriquecimento deles com terras, castelos e tesouros, eles podem ganhar poder sobre os demais e trazer o restante para a dependência deles mesmos" (Harrington, 1977, p. 166, tradução nossa). Diferentemente do que acabara de fazer com Aristóteles, Harrington não precisou inserir a propriedade, porque lá já estava: “[...] fazer senhores de fato e não em nome, dando-lhes castelos e posses e dando-lhes favores de sustento e homens" (Machiavelli, 2010, p. 176, tradução nossa.). O que é interessante, contudo, é que a esta altura dos Discorsi o tema do conflito já havia sido debatido do ponto de vista institucional. Assim, o maquiavelismo de Harrington se assenta na condição igualitária, em termos de propriedade, da república bem ordenada (Harrington, 1977, p. 258). Para Harrington, Maquiavel não percebeu que essa igualdade de posses é também necessária no conflito no poder legislativo (cf. Downs, 1977, pp. 27-28). Portanto, ainda que reconheça que Maquiavel não tratou do tema como deveria, Harrington busca salvá-lo de um completo silêncio sobre a propriedade. Assim, ele "corrige" o florentino sem deixar de enaltecê-lo. 
O conflito, para Harrington, é fundado no interesse de obtenção de propriedade.

\section{Conclusão}

A maioria dos comentadores de Harrington interpreta que ele seja um crítico do conflito e, portanto, um defensor da harmonia e do consenso, pelo fato de o contrabalanceamento dos poderes legislativos levar ao equilíbrio de toda a república. Esquecem, porém, de que não há, a priori, contrariedade entre equilíbrio e conflito. A interpretação de um Harrington avesso ao conflito se deve muito mais a uma extensão dos argumentos ciceronianos e humanistas, ou mesmo do contexto intelectual daquela Inglaterra, do que propriamente ao texto e ao argumento de Harrington. O ponto nevrálgico de sua contribuição à teoria do conflito político reside justamente em inseri-lo em uma dimensão econômica, vinculando-o ao interesse e à propriedade. É fato 170 que, uma vez definido o conflito maquiaveliano em termos de contrariedade de humores antagônicos e inconciliáveis, o conflito de Harrington não pode ser dito maquiaveliano. Por outro lado, não se pode perder de vista que o senado e a assembleia disputam o mesmo objeto: a propriedade. Ambos têm o mesmo interesse que, em conflito institucionalizado, acabam por produzir leis gerais que garantem a liberdade e a igualdade da república. No fundo, o que Harrington busca é uma atualização do conflito de humores divergentes para um conflito por propriedade a partir do interesse.

\section{Luís Falcão}

Doutor em ciência política (Iesp), professor de ciência política da UFF (DCP e PPGCP). Autor de Maquiavel, Montesquieu e Madison: uma tradição republicana em duas perspectivas (2013), Algernon Sidney: um pensador republicano do século XVII (2019) e Algernon Sidney: between modern natural rights and Machiavellian democracy (2020). 


\section{Bibliografia}

ADVERSE, Helton. 2007. Maquiavel, a república e o desejo de liberdade. Trans/form/ação, v. 30, n. 2, pp. 33-52.

ARIENZO, Alessandro. 2009. Machiavelli e machiavellismo tra restaurazione Stuart e governo Orange. In: ARIENZO, Alessandro; BORELI, Gianfranco (org.). Anglo american face of Machiavelli: Machiavelli e Machiavellismo nella cultura anglo-americana (secoli XVI-XX). Monza: Polimetrica. pp. 209-248.

ARISTOTLE. 1932. Politics. Tradução de H. Rackham. Cambridge: Harvard University Press. (Loeb Classical Library, v. 264).

BALESTRIERI, Giovanni G. 2010. Machiavelli e la doppia fondazione della dottrina dei conflitti sociali. La Cultura, n. 3, pp. 459-499.

BARBER, Benjamin. 2004. "Moderno repubblicanesimo?": la promessa della società civile. In: VIROLI, Maurizio (ed.). Libertà politica e virtù civile: significati e percorsi del repubblicanesimo classico. Torino: Fondazione Giovanni Agnelli. pp. 261-281.

BARDUCCI, Marco. 2013. Harrington, Grotius, and the Commonwealth of the Jews, 1656-1660. In: MAHLBERG, Gaby; WIEMANN, Dirk (org.). European contexts for English republicanism. Burlington: Ashgate. pp. 63-80.

BARROS, Alberto Ribeiro G. 2015. Republicanismo inglês: uma teoria da liberdade. São Paulo: Discurso.

BIGNOTTO, Newton. 1991. Maquiavel republicano. São Paulo: Loyola.

BIGNOTTO, Newton. 1994. A má fama na filosofia política: James Harrington e Maquiavel. Discurso, n. 24, pp. 173-191.

BLITZER, Charles. 1970. An immortal commonwealth: the political thought of James Harrington. Yale: Yale University Press.

BORALEVI, Lea Campos. 2002. Classical foundational myths of European republicanism: the Jewish commonwealth. In: SKINNER, Quentin; VELDEREN, Martin van (ed.). Republicanism: a shared European heritage. Cambridge: Cambridge University Press. v. 1, pp. 247-262.

BORALEVI, Lea Campos. 2011. James Harrington's “Machiavellian” antiMachiavellism. History of European Ideas, v. 37, n. 2, pp. 113-119.

CAMBIANO, Giuseppe di. 2000. Polis: uno modello per la cultura europea. Bari: Laterza.

CAPOZZI, Eugenio. 1996. Costituzione, elezione, aristocrazia: la repubblica "naturale" di James Harrington. Napoli: Scientifiche Italiane.

CARANDINI, Guido. 1972. Proprietà, classi e potere politico nella teoria di Harrington. Quaderni di Sociologia, v. 21, n. 4, pp. 444-469.

CENGIAROTTI, Giuseppe. 2010. Antimasque e politica: realtà e finzione nell' Oceana di James Harrington. Rivista Storica Italiana, n. 1, pp. 5-40.

COHEN, Ierome Bernard. 1994. Harrington and Harvey: a theory State based on new physiology. Journal of History of Ideas, v. 55, n. 2, pp. 187-210. 
COTTON, James. 1979. James Harrington as Aristotelian. Political Theory, v. 7, n. 3, pp. 371-389.

COTTON, James. 1981. James Harrington and Thomas Hobbes. Journal of the History of Ideas, v. 42, n. 3, pp. 407-421.

DAVIS, J. Colin. 1981. Pocock's Harrington: Grace, Nature and Art in the Classical Republicanism of James Harrington. The Historical Journal, v. 24, n. 3, pp. 683-697.

DAVIS, J. Colin. 2007. Equality in an unequal commonwealth: James Harrington's republicanism and the meaning of equality. In:

GENTLES, Ian; MORRILL, John; WORDEN, Blair (ed.). Soldiers, writers and statesmen of the English revolution. Cambridge: Cambridge University Press. pp. 229-242.

DOWNS, Michael. 1977. James Harrington. Boston: Twayne.

FINK, Zera Silver. 1962. The classical republicans: an essay on the recovery of a pattern of thought in seventeenth-century England. Eugene: Northwestern University Press.

FUKUDA, Arihiro. 2004. Sovereignty and the sword: Harrington, Hobbes, and mixed government in the English civil wars. Oxford: Clarendon.

GEUNA, Marco. 1998. La tradizione repubblicana e i suoi interpreti: famiglie teoriche e discontinuità concettiuali. Filosofia Politica, v. 1, n. 1, pp. 101-132.

172 GEUNA, Marco. 2013. James Harrington's ancient prudence. In: FIDORA, Alexander; NIEDERBERGER, Andreas; SCATTOLA, Merio (ed.). Phronêsis - Prudentia - Klugheit: das Wissen des Klugen in Mittelalter, Renaissance und Neuzeit: Il sappere del saggio nel medievo, nel rinascimento e nell'età moderna. Porto: Brepols. pp. 289-305.

GOUGH, John Wiedhofft. 1930. Harrington and contemporary thought. Political Science Quarterly, n. 45, pp. 395-404.

HAMMERSLEY, Rachel. 2013. Rethinking the political thought of James Harrington: royalism, republicanism and democracy. History of European Ideas, v. 39, n. 3, pp. 354-370.

HARRINGTON, James. (1977). The political works of James Harrington. Cambridge: Cambridge University Press. $2 \mathrm{v}$.

LURBE, Pierre. 2007. La conception de la république dans Oceana de James Harrington. In: ZARKA, Yves Charles (ed.). Monarchie et république au XVII siècle. Paris: PUF. pp. 73-102.

MACHIAVELLI, Niccolo. 2010. Discorsi sopra la prima deca di Tito Livio. Milano: BUR.

MACPHERSON, Crawford Brough. 1963. Harrington as realist: a rejoinder. Past and Present, n. 24, pp. 82-85.

MCCORMICK, John P. 2011. Machiavellian democracy. Cambridge: Cambridge University Press. 
NEDHAM, Marchamont. 2010. The excellencie of a free-State: Or, the right constitution of a commonwealth. Indianapolis: Liberty Fund.

NEW, John F. H. 1963. Harrington, a realist? Past and Present, n. 24, pp. 82-85.

OSTRENSKY, Eunice. 2011. As várias faces de um ator político. Revista Latinoamericana de Filosofía, v. 37, n. 2, pp. 167-188.

PEDULLÀ, Gabriele. 2011. Machiavelli in tumulto: conquista, cittadinanza e conflitto nei "Discorsi sopra la prima deca di Tito Livio". Roma: Bulzoni Editore. PEZZATO, Franco. 2005. Modelli antichi e pensiero moderno nel repubblicanesimo di James Harrington. Filosofia Politica, n. 2, pp. 219-242. POCOCK, John Greville Agard. 1977. Introduction. In: HARRINGTON, James. The political works of James Harrington. Cambridge: Cambridge University Press. 2. v, pp. 1-154.

POCOCK, John Greville Agard. 1989. Politics, languages and times: essays on political thought and history. Chicago: Chicago University Press.

POCOCK, John Greville Agard. 2003. The Machiavellian moment: Florentine political thought and the Atlantic republican tradition. Princeton: Princeton University Press.

POLIN, Raymond. 1952. Économique et politique au XVIIe siècle:

L'"Oceana" de James Harrington. Revue Française de Science Politique, v. 2, n. 1, pp. 24-41.

RAAB, Felix. 1965. The English face of Machiavelli: a changing interpretation 1500-1700. Toronto: University of Toronto Press.

RAHE, Paul Anthony. 2008. Against throne and altar: Machiavelli and political theory under the English republic. Cambridge: Cambridge University Press.

REMER, Gary. 1995. James Harrington's new deliberative rhetoric: reflections of an anticlassical republicanism. History of Political Thought, v. 16 , n. 4 , pp. 532-557.

REMER, Gary. 2006. After Machiavelli and Hobbes: James Harrington's Commonwealth of Israel. Hebraic Political Studies, v. 1, n. 4, pp. 440-462.

RUSSELL-SMITH, Hugh Francis. 1914. Harrington and his Oceana: a study of a 17th century utopia and its influence in America. Cambridge: Cambridge University Press.

SCHKLAR, Judith. 1959. Ideology Hunting: the case of James Harrington. American Political Science Review, v. 1, n. 53, pp. 662-692.

SCOTT, Jonathan. 2004. Commonwealth principles: republican writing of the English Revolution. Cambridge: Cambridge University Press.

SCOTT, Jonathan. 1993. The rapture of motion: James Harrington's republicanism. In: SKINNER, Quentin; PHILIPSON, Nicholas T (ed.). Political discourse in early modern Britain. Cambridge: Cambridge University Press. pp. 139-164.

SKINNER, Quentin. 1998. Liberty before liberalism. Cambridge: Cambridge University Press. 
SOMOS, Mark. 2013. Irenic Secularization and the Hebrew Republic in Harrington's Oceana. In: MAHLBERG, Gaby; WIEMANN, Dirk (ed.). European contexts for English Republicanism. Burlington: Ashgate. pp. 81-104.

STRUMIA, Anna. 1991. L'immaginazione repubblicana: Sparta e Israele nel dibattito filosofico-politico dell'età di Cromwell. Firenze: Casa Editice le Lettere.

SULLIVAN, Vickie B. 2004. Machiavelli, Hobbes and the formation of the liberal republicanism in England. Cambridge: Cambridge University Press.

TAHVANAINEN, Antti. 2012. Rhetoric and public speech in English Republicanism: 1642-1681. Helsinki: Helsinki University Print.

TOLAND, John. 1700. The dedication, the preface e the life of James Harrington. In: HARRINGTON, James. The Oceana and other works of James Harrington, with an account of his life by John Toland. London: Printed for T. Becket, and T. Cadell, in the strand; and T. Evans, in King Street, convent Garden. pp. i-xl.

VATTER, Miguel. 2010. Between form and event: Machiavelli's theory of political theory. Boston: Kluwer Academic, 2010.

WETTERGREEN, John A. 1988. Harrington's liberal republicanism. Polity, v. 20, n. 4, pp. 665-687.

WORDEN, Blair. 1994. Harrington's Oceana: origins and aftermath, 1651-1660. In: WOOTTON, David (ed.). Republicanism, liberty, and $174 \quad$ pp. 111-138.

WOOTTON, David. 1994. James Harrington and The Commonwealth of Oceana, 1656. In: WOOTTON, David (ed.). Republicanism, liberty, and commercial society: 1649-1776. Stanford: Stanford University Press, pp. 82-110.

ZAGORIN, Perez. 1997. A history of political thought in the English revolution. Bristol: Thoemmes. 


\section{UMA TEORIA DO CONFLITO NÃO MAQUIAVELIANO: O CASO DE JAMES HARRINGTON}

\section{LUÍS FALCÃO}

Resumo: Este artigo argumenta que James Harrington é um defensor do conflito político, de um modo diverso ao de Maquiavel, porque para esse os humores (dos grandes e do povo) estão em contrariedade. Para Harrington, o conflito se faz a partir do interesse pela riqueza na forma de propriedade. Os homens, apesar de possuírem o mesmo interesse, têm capacidades distintas de realizá-lo, configurando a natural aristocracy. Por isso, aqueles que possuem sabedoria, os senadores, devem propor as leis e o povo, soberano da assembleia, deve escolhê-las. Tal divisão de poderes e separação de funções supõe um conflito institucionalizado entre as casas. Em parte, o senado tem seus interesses atendidos, em parte, a assembleia tem o seu, pois senão, nenhuma lei seria aprovada. A realização parcial do interesse, por motivos diversos, confirma o maquiavelismo de Harrington.

Palavras-chave: James Harrington; Maquiavel; Conflito; Interesse.

\section{A NON-MACHIAVELLIAN THEORY OF CONFLICT: THE CASE OF JAMES HARRINGTON}

Abstract: This paper considers James Harrington a champion of political conflict, in a different manner to that of Machiavelli. Machiavelli argues that there are two kinds of humors and Harrington that conflict is made by one single interest: riches and property. Men, although possessing the same interest, have distinct abilities to achieve it, thus forming natural aristocracy. Therefore, those who have wisdom, the senators, must propose laws, and the people, rulers of the assembly, must choose them. Such division of powers and separation of functions implies an institutionalized 
conflict between hierarchies. In part, the senate has its interests met, in part, the people has their own, otherwise no law would be approved. The partial achievement of interests, for different reasons, confirms Harrington's Machiavellism.

Keywords: James Harrington; Machiavelli; Conflict; Interest.

Recebido: 19/10/2018Ａprovado: 29/09/2020 